Review Article

\title{
Bacteriophage therapy: a potential solution for the antibiotic resistance crisis
}

\author{
Zhabiz Golkar, Omar Bagasra, Donald Gene Pace \\ South Carolina Center for Biotechnology, Claflin University, Orangeburg, United States
}

\begin{abstract}
The emergence of multiple drug-resistant bacteria has prompted interest in alternatives to conventional antimicrobials. One of the possible replacement options for antibiotics is the use of bacteriophages as antimicrobial agents. Phage therapy is an important alternative to antibiotics in the current era of drug-resistant pathogens. Bacteriophages have played an important role in the expansion of molecular biology and have been used as antibacterial agents since 1966. In this review, we describe a brief history of bacteriophages and clinical studies on their use in bacterial disease prophylaxis and therapy. We discuss the advantages and disadvantages of bacteriophages as therapeutic agents in this regard.
\end{abstract}

Key words:. antibiotic resistance; bacteriophage; infectious disease

J Infect Dev Ctries 2014; 8(2):129-136. doi:10.3855/jidc.3573

(Received 22 March 2013 - Accepted 10 September 2013)

Copyright ( $\odot 2014$ Golkar et al. This is an open-access article distributed under the Creative Commons Attribution License, which permits unrestricted use, distribution, and reproduction in any medium, provided the original work is properly cited.

\section{Introduction}

In the golden age of the discovery of antibiotics, innumerable lives were saved. These highly potent "miracle" drugs are no longer as effective as they were a half a century ago [1]. We are now entering an era in which bacterial infections, such as septicemia and ventilator-associated pneumonia, might no longer be successfully treated with antibiotics [1]. A few years ago, New Yorker magazine aptly satirized American attitudes toward antibiotics with a cartoon of a doctor's office sign: "Don't forget to take a handful of our complimentary antibiotics on your way out."

\section{Antibiotics resistance in United States}

In 2008, the Infectious Disease Society of America (IDSA) confirmed that the United States and the rest of the world are in the midst of an emerging crisis of antibiotic resistance for microbial pathogens [2]. Antibiotic resistance is fueled by misuse and overuse of antibiotics. Bacteria become resistant to the very medicine developed to treat and cure the infections they cause. Epidemic antibiotic resistance has been described in numerous pathogens in varying contexts, including, but not limited to, a global pandemic of methicillin-resistant Staphylococcus aureus (MRSA) infection [3], vancomycin-resistant enterococci (VRE), and a growing number of additional pathogens that are developing resistance to many common antibiotics.
The global spread of drug resistance among common respiratory pathogens, including Streptococcus pneumonia [4-5] and Mycobacterium tuberculosis [6], and epidemic increases in multidrug-resistant (and, increasingly, truly pan-resistant) Gram-negative bacilli [7], impacts clinicians practicing in every field of medicine. Given their scope of effect and significant impact on morbidity and mortality, multidrug-resistant microbes are considered to be a substantial threat to US public health and national security by the National Academy of Science's Institute of Medicine [8], the federal Interagency Task Force on Antimicrobial Resistance (Interagency Task Force) [9], and the Infectious Diseases Society of America (IDSA) [2].

In the United States, an estimated $23 \times 10^{6} \mathrm{~kg}$ of antibiotics are used annually; about half of these are provided to people, and the rest are manufactured for agriculture and given to animals including chickens, cows, pigs, and other livestock [10]. Livestock are fed antibiotics not because they are infected, but for preventive purposes. These antibiotics are ingested by humans when they consume food. In hospitals, antibiotics are generally administered parenterally, while in the community they are delivered mostly as oral preparations. About $7 \times 10^{6} \mathrm{~kg}$ of antibiotics, chiefly penicillins and tetracyclines, are used as growth promotants in food and animals [11]. Some 45 $\times 10^{3} \mathrm{~kg}$ of tetracyclines and streptomycin are used as 
pesticides for agriculture; these are sprayed on fruit trees in the southern and western United States [11]. While this last amount seems small compared with overall antibiotic use, the geographical spread can be considerable. Some strains of Erwinia amylovora, the bacterial target of these drugs, have become resistant to antibiotics. While the emergence of resistant bacteria in agriculture is a small part of the overall global microbial resistance pool, it is an example of widespread antibiotic use in which the environment of microorganisms is besieged with growth-inhibiting agents. The result is the survival of those organisms that bear transposons and other mechanisms for selfpreservation, leaving environmental microorganisms that are largely resistant [11].

Drug-resistant infections take a staggering toll in the United States and across the globe. Just one organism, methicillin-resistant Staphylococcus aureus (MRSA), kills more Americans every year than emphysema, HIV/AIDS, Parkinson's disease, and homicide combined [12]. In recent years, drugresistant forms of Neisseria gonorrhoeae, a causative agent of gonorrhea, the second most commonly reported infectious disease in the United States, have begun to emerge. The National Institute of Allergy and Infectious Diseases (NIAID) is investigating at several angles why the bacteria that cause gonorrhea are becoming resistant to treatments, and is investigating new ways to treat and prevent the disease [13].

Currently, the Centers for Disease Control and Prevention (CDC) recommends that most cases of gonorrhea in the United States be treated with a combination of two drugs: a cephalosporin and a second antibiotic (e.g., azithromycin or doxycycline). At this time of rising antibiotic resistance, it is important that more than one type of treatment be available for infections such as gonorrhea, so that if the bacteria are resistant to one type of drug, other options are available [14].

\section{Economic factor (US facts)}

Giving the underlying economic factors, antibiotic-resistant infections are a burden to US families and the US health care system. The medical cost per patient suffering from an antibiotic-resistant infection ranges from $\$ 18,588$ to $\$ 29,069$ USD [15]. These costs per patient total over $\$ 20$ billion in health care system costs each year in the United States. The duration of hospital stays for patients with antibioticresistant infections was found to be extended by 6.412.7 days [15]. During this time, patients are unable to work and thus lose wages. These costs to US households total over $\$ 35$ billion each year [15]. Nearly two million Americans per year develop hospital-acquired infections (HAIs), resulting in 99,000 deaths, the vast majority of which are due to antibacterial-resistant pathogens [16]. Two common HAIs alone (sepsis and pneumonia) killed nearly 50,000 Americans and cost the US health care system more than $\$ 8$ billion in 2006 [17]. Based on studies of the costs of infections caused by antibiotic-resistant pathogens versus antibiotic-susceptible pathogens, the cost of antibiotic-resistant infections to the US health care system is $\$ 21$ billion to $\$ 34$ billion each year and more than eight million additional hospital days [18].

New antibiotic development has slowed to a standstill due to market failure and regulatory disincentives. Antibiotics are not as profitable as other drugs (e.g., drugs to treat diabetes, asthma, or gastroesophegeal reflux, which patients take for years). Also, the US Food and Drug Administration has long delayed publishing workable guidelines that describe how companies should design antibiotic clinical trials. Moreover, once a new antibiotic makes it to market, physicians hold it in reserve for only the worst cases, rather than promptly prescribing it to their patients, due to fear of drug resistance. These economic and regulatory disincentives have made it far too difficult for companies to continue developing new antibiotics [19].

If we do not act immediately, we face a future that may resemble the days before these "miracle" drugs were developed: one in which people die of common infections, and where many medical interventions we take for granted - including surgery, chemotherapy, organ transplantation, and care for premature infants become impossible [20]. Besides antibiotics, other agents meant to destroy bacteria are also misused, namely the surface antibacterials now available in many household products. These too enter the environment. The stage is thus set for an altered microbial ecology, not only in terms of resistant versus susceptible bacteria, but also in terms of the kinds of microorganisms surviving in the treated environment. In order to curb the resistance problem, we must encourage the return of the susceptible commensal flora. They are our best allies in reversing antibiotic resistance [11].

In December 2011, the outgoing Administrator of the Centers for Medicare and Medicaid Services, Dr. Donald Berwick, asserted that $20 \%$ to $30 \%$ of health care spending is waste. He listed as causes for the waste (1) overtreatment of patients, (2) the failure to 
coordinate care, (3) the administrative complexity of the health care system, and, (4) burdensome rules [21].

In 2007, the Infectious Diseases Society of America (IDSA) issued a public policy stating that physicians must take care to prescribe antibiotics appropriately to minimize the rate of spread of drug resistance [22]. We must educate each other, our patients, the media, and politicians about this problem. Only the medical community can provide an accurate perspective and rational balance to this issue [23]. For example, although bioterrorism is an important theoretical threat, the total death toll from the anthrax scare several years ago was five people, and the last death due to smallpox in the United States occurred almost 60 years ago. In contrast, as of the year 2000, the CDC reported that approximately 70,000 deaths due to nosocomially acquired, drug-resistant infections occurred per year in hospitals throughout the United States [24]. The number is almost certainly dramatically higher in 2013 [22].

\section{Phage history}

In this pretext, we will not review the old literature that has been reviewed elsewhere $[25,26]$. To better understand future prospects and phage application in modern medicine, however, some basic history is necessary. The biblical Book of Kings relates how the prophet Elisha cured general Naaman's disease by commanding him to bathe seven times in the river Jordan. Since ancient times, there have been documented reports of river waters having the ability to cure infectious diseases such as leprosy [27]. But, in 1896, the British bacteriologist Ernest Hankin reported antibacterial activity against Vibrio cholerae, which he observed in the Ganges and Jumna rivers in India. He suggested that an unidentified substance was responsible for this phenomenon and for limiting the spread of cholera epidemics. Two years later, Gamaleya, the Russian bacteriologist, observed a similar phenomenon while working with Bacillus subtilis [28].

From 1898 to 1918 , others had similar observations of what is thought to be the bacteriophage phenomenon. It was not until 1914, however, that another British bacteriologist, Frederick Twort, advanced the hypothesis by proposing that it may have been due to, among other possibilities, a virus. For various reasons, including financial difficulties, Twort did not pursue this finding [29].

A French-Canadian microbiologist, Felix d'Herelle, first observed in 1910 the bacteriophage phenomenon while studying microbiologic methods of controlling locusts in Mexico. In the lab, when he spread some cultures on agar, he observed round zones without growth, which he called plaques, and asserted they were caused by viral parasites. Six years later, he proposed the name "bacteriophage," or bacteriumeater [29].

In 1917, d'Herelle began testing his phage in human patients. Under the clinical supervision of Professor Victor-Henri Hutinel at the Hospital des Enfants-Malades in Paris, he demonstrated the safety of his phages by ingesting them. The next day, he demonstrated their efficacy by administering them to a 12-year-old boy with severe dysentery. The patient's symptoms ceased after a single treatment, and he made a complete recovery. Dr. d'Herelle's anti-dysentery phage was then administered to three additional patients, all of whom began to recover within 24 hours of treatment [58]. In 1923, two physicians from Baylor University's College of Medicine reported successful results from one of their phage therapy trials conducted in United States, and concluded that "the bacteriophage holds enormous possibilities as a new weapon for fighting infectious disease" [31].

\section{Advantage of phage therapy over antibiotics}

On reflection of these studies, perhaps it would be wise to reconsider and rediscover phage therapy. Bacteriophages are very specific to their hosts, so this minimizes the chance of secondary infections, but antibiotics do target both pathogens and normal flora of patients, which can cause the secondary infections or sometimes superinfections. Also, bacteriophages replicate at the site of infection where they are mostly needed to lyse the pathogens, but antibiotics travel throughout the body and do not concentrate at the site of infection. No side effects have been reported during or after phage application, but resistant bacteria, allergies (sometimes even fatal anaphylactic reaction), and secondary infections are the common side effects of antibiotics treatment [32]. Lastly, bacteriophages are environmentally friendly and are based on natural selection, isolating and identifying bacteria in a very rapid process compared to new antibiotic development, which may take several years, may cost millions of dollars for clinical trials, and may also not be very cost effective [33].

Moreover, although bacteria can become resistant to phages, phage resistance is not nearly as worrisome as drug resistance. Like bacteria, phages mutate and therefore can evolve to counter phage-resistant bacteria [31,34]. Furthermore, the development of 
phage resistance can be forestalled altogether if phages are used in cocktails (preparations containing multiple types of phages) and/or in conjunction with antibiotics. In fact, phage therapy and antibiotic therapy, when coapplied, are synergistic [31,35].

\section{Clinical use of phage therapy}

Production and usage of phages for therapy and prophylaxis continued on a small scale, even after the advent and diffusion of antibiotics in Western Europe and the United States in the 1950s and 1960s. Several companies had small-scale productions of phage preparations for various purposes [36]. Human phage therapy has been practiced in France since 1919, when d'Herelle first successfully treated several children who were suffering from severe dysentery at the Hospital des Enfants Malades in Paris, using the phage he had first isolated from clinical samples [37]. Since then, the Pasteur Institute in France produced phage preparations against various pathogens (Pseudomonas, Staphylococcus, Escherichia coli, and Serratia) until 1974. These phages were used mainly against skin infections, septicemia, osteomyelitis, wound infections, urinary tract infections, and middle ear and sinus infections. There continued to be regular scientific reports on phage therapy in France until at least 1979. The reason that phage therapy was terminated, we believe, was that antibiotics were thought to "cure" infection without ever having to test for the real causative agents and thus became an easy way to treat patients. In developing nations, this practice is so common that one can purchase a range of antibiotics at a pharmacy without a prescription.

In Poland, thousands of patients have been treated with phages, particularly in association with the Hirszfeld Institute of Immunology and Experimental Therapy in Wrocław, which was founded in 1954 [38]. In the United States, phages have been used mainly for the preparation of human and animal vaccines. Staphylococcal phage lysate (SPL) produced in the United States was used for animal protection. With safety trials completed in 1959, SPL was licensed for human therapeutic usage [39] and was administrated by several different routes: intranasal application by aerosol, topically, orally, subcutaneously, and even intravenously.

Interest in phages and the use of phage therapy spread quickly to the United States during the 1920s and 1930s [37,40]. One of the first studies of subcutaneous phage administration was carried out at the Michigan Department of Health, where Larkum reported treatment of 208 patients with chronic furunculosis; $78 \%$ of the patients had no recurring infections for at least six months after treatment and only 3\% showed no improvement. There have been reported remarkable successes with staphylococcal septicemia and meningitis. Also, several studies [41] reported the treatment of MRSA using phages, which can be accomplished by local application for local infections or, if necessary, and with substantially more caution, more systemic dosing, including intraperitoneally for systemic infections. [42]

Another major infectious disease problem in the United States are respiratory infections, which can be differentiated into numerous types; phage therapy is limited in efficacy in those that have a bacterial etiology. Klebsiella pneumoniae is another Gramnegative bacteria that causes severe nosocomial diseases such as septicemia, pneumonia, and urinary tract infection in immunocompromised individuals [43]. In the past two decades, a community-acquired infection by invasive $K$. pneumoniae first emerged in Asia [44] and was then found worldwide [45]. About $80 \%$ of nosocomial infections caused by $K$. pneumoniae are due to multidrug-resistant strains. The emergence of antibiotic-resistant bacterial strains necessitates the exploration of alternative antibacterial therapies. One study [46] documented the ability of bacteriophages to treat mice infected with $K$. pneumoniae. Phage SS specific for $K$. pneumoniae B5055 is well characterized, and its potential as a therapeutic agent is evaluated in an experimental model of $K$. pneumoniae-mediated lobar pneumonia [46]. Many physicians started to consider phage treatment of respiratory infections, differentiating primarily between those cases that either do or do not involve cystic fibrosis (CF). Previously, phage therapy has been reported to be successful in treating pneumonia in six cancer patients [47].

Overall phage therapy efficacy was demonstrated in a clinical trial (late 1950s to early 1960s) in which 607 patients, all of whom had failed to respond to conventional treatment by antibiotics, were treated by phage therapy. The results were reportedly good: $80 \%$ of the patients recovered, $18 \%$ improved, and only $2 \%$ exhibited no changes. Furthermore, no side effects were reported. Unfortunately, owing to regulatory pressure, production of SPL for human therapy was suspended in the 1990s, and the preparation is currently approved and marketed only for veterinary applications [38].

Propionibacterium acnesis is a dominant member of the skin microflora (also called the microbiome or 
the microbiota) and has also been implicated in the pathogenesis of acne. However, little is known about the bacteriophages that coexist with and infect this bacterium. In 2012, a phage research team in Los Angles discovered phage 11P, which is effective on $P$. acnesis [48]. Surprisingly, this phage shares a broad ability to kill clinical isolates of $P$. acnes and other skin isolate bacteria that cause acne. These investigators believe that these phages display numerous features that would make them ideal candidates for the development of a phage-based therapy for acne.

\section{Phage application as biocontrol}

Effective elimination of pathogenetic bacteria from gastrointestinal diseases using phage preparation has been demonstrated in multiple experiments that focused on the therapeutic use of phages [49]. The therapeutic effect of the phages can be limited to a decrease in the pathogen's population down to a point at which the immune system can effectively control its reproduction. Several current strategies to combat livestock-associated pathogens such as toxinogenic $E$. coli, Campylobacter, and Salmonella are direct extensions of "classical" phage therapy approaches in that they focus on targeting the bacteria in animals before slaughter [50]. On the other hand, food contamination, for instance with Listeria monocytogenes, is more likely to occur during food processing, which consequently is the most reasonable time point for phage biocontrol of this pathogen. In this context, the United States Food and Drug Administration has recently approved the use of antiListeria phage food additives, and conferred the generally recognized safe status to another antiListeria phage [83]. Other authors [51] have treated mice, sheep, and cattle with phages KH1 and SH1. Oral application of either SH1 or the combination of $\mathrm{KH} 1$ and $\mathrm{SH} 1$ in mice resulted in the complete eradication of target bacteria. A recent study addressed the problem of Enterobacter sakazakii growing in reconstituted infant formula milk [52] and employed newly isolated phages against this infectious pathogen. It is interesting to note that the T4-like phage ESP 732-1 was able to effectively suppress the growth of the organism in prepared infant formula, both at $24^{\circ} \mathrm{C}$ and $37^{\circ} \mathrm{C}$. The killing effect was dose-dependent, and the highest phage concentration $\left(10^{9} \mathrm{PFU} / \mathrm{mL}\right)$ was most effective and able to completely eradicate the target organisms [31]. As an alternative to such in vivo treatments, phages can be applied or mixed directly onto or into the food product [31].

\section{Phages as vaccines or therapeutic delivery systems}

Despite the large number of publications on phage therapy, there are very few reports in which the pharmacokinetics of therapeutic phage preparations are clearly defined. The few publications available on the subject $[3,4]$ suggest that phages get into the bloodstream of laboratory animals (after a single oral dose) within two to four hours, and are found in the internal organs (liver, spleen, kidney, etc.) within approximately ten hours. Also, data concerning the persistence of administered phages indicate that phages can remain in the human body for relatively prolonged periods of time - up to several days [3]. However, additional research is needed in order to obtain rigorous pharmacological data concerning lytic phages, which include full-scale toxicological studies, before lytic phages can be used therapeutically in Western countries $[52,53]$. The specificity of targeting by phages may be exploited for their use as a delivery system for bacterial molecules. Similarly, non-lytic phages engineered to produce antimicrobial proteins were effective in a systematic mouse model for $E$. coli [54]. It has been reported that phages alone can disrupt biofilm colonies of target organisms, such as Staphylococcus epidermidis growing on silicon catheters [55]. Phages have also been bioengineered to attack biofilm. An E. coli phage, T7, was modified to express dispersin B, an enzyme that degrades b-1, 6$\mathrm{N}$-acetyld-glucosamine (an important component of biofilm) in such a way that the enzyme is released into the extracellular milieu during bacterial cell lysis [56]. Targeted gene deletions have produced phages with the capacity to bind to their target receptors and inject their DNA but not to replicate or lyse bacteria [57]. This potentially results in the inhibition of toxin production and in bacterial killing. Exposure of methicillin-resistant $S$. aureus to this construction results in $\mathrm{a} \geq 99.9 \%$ kill rate in five minutes with an inoculum of $1 \times 10^{5}$ organisms and $\mathrm{a} \geq 99.9 \%$ kill rate in ten minutes with $1 \times 10^{7}$ organisms [57].

\section{Rediscovering phage therapy}

A detailed description of research in phage therapy is beyond the scope of this review; however, significant research consisting of completed or planned phase I trials have been reported from Britain, Belgium, Australia, and India. Perhaps regulatory approvals for some non-medical applications of phage therapy (biocontrol), which have been granted in the United States, may be of interest. The Food and Drug 
Administration has amended the US food additive regulations to provide for the safe use of bacteriophages on ready-to-eat meat against Listeria monocytogenes [58]. The idea that ready-to-eat meat can be treated if contaminated with Listeria bacteria, while a doctor could not get a pharmaceutical grade phage therapy product when faced with a patient suffering listeriosis, strikes these authors as absurd, especially considering the recalls of various foods due to contamination with Listeria. The approved product is manufactured by Intralytix [59], and ListShield targets Listeria monocytogenes in foods and food processing facilities. Agriphage, commercially available from Omnilytics [60], is primarily used to treat bacterial damage of tomatoes and peppers and has been recognized to be compatible with organic food production. Biocontrol applications have recently been described [61]. Interestingly, both editors are Canadian, one of them a government employee and the other a university professor, despite the fact that there have been no regulatory approvals for phage therapy products in Canada. The first question every presenter on phage therapy is asked is: If I were to have an infection that antibiotics cannot treat effectively, is there any place where I can receive phage therapy right now? There are two countries where treatment with phages is routinely available in Europe: Georgia [62] and Poland (Russia probably also uses phage therapy, but much less information is available). More recently, the Wound Care Center in Lubbock, Texas used phage therapy [63].

\section{Conclusions}

Bacteriophages are a diverse group of viruses which are easily manipulated, and therefore have potential uses in biotechnology, research, and therapeutics. The aim of this review article is to enable the wide range of researchers, scientists, and biotechnologist who are putting phages into practice to accelerate progress and development in the field of biotechnology. It is a fact that, now, nearly 70 years later, we have reached a critical point in treating infectious diseases: new drugs are not being developed at anywhere near the pace necessary to keep ahead of the natural ability of bacteria to evolve and defend themselves against antibiotics. The result is that some of our most powerful drugs are becoming useless. Based on our previous studies and examples in this text, we think the use of bacteriophages to treat and/or prevent bacterial infections is promising. The therapeutic use of bacteriophages, possibly in combination with antibiotics, may be a valuable approach. There is no doubt that bacteriophage application in biocontrol of pathogens will be beneficial for food safety and public health in the United States. It is critically important to notice that there are some concerns about the use of phages that include safety and efficacy issues, as well as immune response to the administered phages. Growth optimization and phage purification strategies are also issues that must be addressed. The pharmacokinetics of different phages may differ from one another, and this will require concerted efforts to analyze. Due to the rapid progress in the fields of biotechnology and molecular biology, it is hoped that phages, which are presently abundant in the biosphere, could answer many questions.

After reflection on previous studies, we maintain that it may be wise to reconsider the fact that phages can be used as biocontrol agents not only in agriculture, but also in the petroleum industry. Moreover, phages are used as vehicles for vaccines (both DNA and protein), for the detection of pathogenic bacterial strains, and as display systems for many proteins and antibodies. The details given in this article give a glimpse of the large range of applications to which phages can contribute in the fields of biotechnology and medical science. The applications of phages range from the diagnosis of the disease, through phage typing and its prevention (phage vaccine), to treatment (phage therapy). Phages could be useful to humans in many ways. By making a cocktail of phages, it would become easy to treat a wide variety of drug-resistant bacterial infections that are otherwise resistant to the latest generations of antibiotics. A phage can be used individually to treat a bacterial infection by lysing the bacterial cell, as it has the lytic potential. At the same time, the versatility of phages would allow us to use the antibodies against the bacteria that have been displayed on the phage surface. Similarly, a protective antigen could be delivered as a DNA or phage display vaccine. A mixture of phages that are modified genetically would be more helpful in addressing all these problems. Phages have also helped with the food spoilage problem, and treatment of bacterial infections of plants and fruits.

\section{References}

1. Centers for Disease Control. Antimicrobial resistance: a growing threat to public health. Atlanta: Division of Healthcare Quality Promotion; National Center for Infectious Diseases (2002) Division of Healthcare Quality Promotion, National Center for Infectious Diseases, Centers for Disease Control. 
2. Infectious Diseases Society of America (2004) Bad bugs, no drugs: as antibiotic discovery stagnates, a public health crisis brews. Alexandria, Infectious Diseases Society of America. Avaliable

http://www.fda.gov/ohrms/dockets/dockets/04s0233/04s0233-c000005-03-IDSA-vol1.pdf

3. Moran GJ, Krishnadasan A, Gorwitz RJ, Fosheim GE, McDougal LK, Carey RB, Talan DA (2006) Methicillinresistant $S$. aureus infections among patients in the emergency department. N Engl J Med 355: 666-674.

4. Whitney CG, Farley MM, Hadler J, Harrison LH, Lexau C, Reingold A (2000) Increasing prevalence of multidrugresistant Streptococcus pneumoniae in the United States. N Engl J Med 343: 1917-1924.

5. Grant GR, Lederman JA, Brandstetter RD (1997) T.G. Heaton, tuberculosis, and artificial pneumothorax: once again, back to the future? Chest 112: 7-8.

6. Nachega JB, Chaisson RE (2003) Tuberculosis drug resistance: a global threat. Clin Infect Dis 36: 24-30.

7. Levin AS, Barone AA, Penco J (1999) Intravenous colistin as therapy for nosocomial infections caused by multidrugresistant Pseudomonas aeruginosa and Acinetobacter baumannii. Clin Infect Dis 28: 1008-1011.

8. Smolinski MS, Hamburg MA, Lederberg J (2003) Microbial threats to health: emergence, detection, and response. Washington, DC: Institute of Medicine.

9. Antibiotic/antimicrobial resistance: action plan. Atlanta: US Department of Health and Human Services Centers for Disease Control and Prevention. (2013) Available: http://www.cdc.gov/drugresistance/actionplan. Accessed on 20 December 2012

10. Harrison PF \& Lederberg J, editors (1998) Antimicrobial Resistance: Issues and Opinions. Workshop Report. Washington, DC: National Academy Press.

11. Levy SB (2002) Factors impacting on the problem of antibiotic resistance. J. Antimicrob Chemother 49: 25-30.

12. Klevens RM, Morrison MA, Nadle J, Petit S, Gershman K, Ray S, Harrison LH, Lynfield R, Dumyati G, Townes J, Craig AS, Zell ER, Fosheim GE, McDougal LK, Carey RB, Fridkin SK (2007) Invasive methicillin resistant Staphylococcus aureus infections in the United States. JAMA 298: 17631771.

13. Folster JP, Johnson PJT, Jackson L, Dhulipali V, Dyer DW, Shafer WM (2009) MtrR modulates rpoH expression and levels of antimicrobial resistance in Neisseria gonorrhoeae. J Bacteriol 191: 287-297.

14. Mercante AD, Jackson L, Johnson PJ, Stringer VA, Dyer DW, Shafer WM (2012) MpeR regulates the mtr efflux locus in Neisseria gonorrhoeae and modulates antimicrobial resistance by an iron-responsive mechanism. Antimicrob Agents Chemother 56: 1491-1501.

15. Haddix AC, Teutsch SM, Corso PS, editors (2003) Prevention effectiveness: a guide to decision analysis and economic evaluation. New York: Oxford University Press p 345-357.

16. Klevens RM, Edwards JR, Richards CL Jr, Hortan T, Gaynes R, Pollock D, Cardo D (2007) Estimating health careassociated infections and deaths in U.S. hospitals, 2002. Public Health Rep 122: 160-166.

17. Eber MR, Laxminarayan R, Perencevich EN, Malani A (2010) Clinical and economic outcomes attributable to health care-associated sepsis and pneumonia. Arch Intern Med 170: 347-353.
18. Filice GA, Nyman JA, Lexau C (2010) Excess costs and utilization associated with methicillin resistance for patients with Staphylococcus aureus infection. Infect Control Hosp Epidemiol 31: 365-367.

19. Facts about Antibiotic Resistance (2012) Infectious Diseases Society of America. Available at: http://www.idsociety.org/AR_Facts. Accessed on December $12,2012$.

20. Infectious Diseases Society of America( IDSA)- (2011). Facts about Antibiotic Resistance. Availble at : http://www.idsociety.org/AR_Facts/ Accessed on April 5, 2011.

21. Pear R (2011) Health Official Takes Parting Shot at "Waste" By Key Obama Health Official. New York Times. Available: http://www.nytimes.com/2011/12/04/health/policy/partingshot-at-waste-by-key-obama-health-official.html?_r=1\&. Accessed 20 December 2012.

22. Spellberg B, Powers JH, Brass EP, Miller LG, Edwards JE (2008) The Epidemic of Antibiotic-Resistant Infections:A Call to Action for the Medical Community from the Infectious Diseases Society of America. Clinical Infectious Diseases 46: 155-164.

23. Dellit TH, Owens RC, McGowan JE, Gerding DN, Weinstein RA, Burke JP, Huskins WC, Paterson DL, Fishman NO, Carpenter CF, Brennan PJ, Billeter M, Hooton TM (2007) Infectious Diseases Society of America and the Society for Healthcare Epidemiology of America guidelines for developing an institutional program to enhance antimicrobial stewardship. Clin Infect Dis 44: 159-177.

24. Infectious Diseases Society of America (2004) Bad bugs, no drugs: as antibiotic discovery stagnates, a public health crisis brews. Available: www.fda.gov/ohrms/dockets/.../04s-0233c000005-03-IDSA-vol 1.pdf Accessed on ,20 December 2012

25. Nakai M, Park T, Nakai SC (2002) Park Bacteriophage therapy of infectious diseases in aquaculture. Res. Microbiol 153: $13-18$.

26. Cerveny KA, DePaola A, Duckworth DH, Gulig PA (2002) Phage therapy of local and systemic disease caused by Vibrio vulnificus in iron-dextran-treated mice. Infect. Immun 70: 6251-6262.

27. Keen EC (2012) Felix d'Herelle and Our Microbial Future. Future Microbiology 7: 1337-1339.

28. Adhya S, Merril C (2006) The road to phage therapy. Nature 443: 754-755.

29. Duckworth DH (1976) Who discovered bacteriophage? Bacteriol Rev 40: 793-802.

30. Kuchment A (2012) The Forgotten Cure: The Past and Future of Phage Therapy. Springer, New York. $170 \mathrm{p}$.

31. Ho K (2001) Bacteriophage therapy for bacterial infections: rekindling a memory. Perspect Biol Med 44: 1-16.

32. Sulakvelidze A, Alavidze Z, Morris GJ (2001) Antimicrob Agents Chemother 45: 649-659.

33. Weber-Dabrowska B, Mulczyk M, Gorski A (2000) Bacteriophage therapy of bacterial infections: an update of our institute's experience. Arch Immunol Ther Exp (Warsz) 48: 547-551.

34. Matsuzaki S, Rashel M, Uchiyama J, Sakurai S, Ujihara T, Kuroda M, Ikeuchi M, Tani T, Fujieda M, Wakiguchi H, Imai S (2005) Bacteriophage therapy: a revitalized therapy against bacterial infectious diseases. J Infect Chemother 11: 211-219. 
35. Kutateladze M, Adamia R (2010) Bacteriophages as potential new therapeutics to replace or supplement antibiotics. Trends Biotechnol 28: 591-595.

36. Hausler T (2006) Viruses vs Superbugs. A Solution to the Antibiotic Crisis? London; New York: Macmillan. 256 p.

37. Kutter E (2008) Phage Therapy: Bacteriophages as naturally occurring antimicrobials. In: Goldman E, Green LH, editors. Practical Handbook of Microbiology. Boca Raton: CRC Press. 713-730.

38. Slopek S, Kucharewicz-Krukowska A, Weber-Dabrowska B, Dabrowski M (1985) Results of bacteriophage treatment of suppurative bacterial infections. VI. Analysis of treatment of suppurative staphylococcal infections. Arch Immunol Ther Exp (Warsz) 33: 261-273.

39. Salmon GG, Symonds M (1963) Staphlilo phage lysate therapy in chronic Staphylococcal infections. J Med Soc N J 60: 188-193.

40. Eaton MD, Bayne JS (1934) Bacteriophage therapy: Review of the principles and results of the use of bacteriophage in the treatment of infections (III) J Am Med Assoc 103: 19341939.

41. Schless RA (1932) Staphylococcus aureus meningitis: treatment with specific bacteriophage. Am J Dis Child 44: 813-822.

42. Straub ME, Applebaum M (1933) Studies on commercial bacteriophage products. J Am Med Assoc 100: 110-113.

43. Abuladze T, Li M, Marc Y (2008) Bacteriophages reduce experimental contamination of hard surface: Tomato, Spinach, Broccoli and ground beef by E.coli 0157:H7 Appl Environ Microbiol 74: 6230-6238.

44. Podschun R, Ullmann U (1998) Klebsiella spp. as nosocomial pathogens: epidemiology, taxonomy, typing methods, and pathogenicity factors. Clin Microbiol Rev 11: 589-603.

45. Fung CP, Chang FY, Lee SC, Hu BS, Kuo BI, Liu CY, Ho M, Siu LK. (2002) A global emerging disease of Klebsiella pneumonia liver abscess: is serotype $\mathrm{K} 1$ an important factor for complicated endophthalmitis? Gut 50: 420-424.

46. Cahill M, Chang B, Murray A (2000) Bilateral endogenous bacterial endophthalmitis associated with pyogenic hepatic abscess. Br J Ophthalmol 84: 14-36.

47. Chhibber S, Kaur S, Kumari S (2008) Therapeutic potential of bacteriophage in treating Klebsiella pneumoniae B5055meiated lobar pneumonia in mice. J Med Microbiol 12: 15081513.

48. Weber-Dabrowska B, Mulczyk M, Górski A (2001) Bacteriophage therapy for infections in cancer patients. Clin Appl Immunol Rev 1: 131-134.

49. Marinelli LJ, Fitz-Gibbon S, Hayes C, Bowman C, Inkeles M, Loncaric A, Russell DA, Jacobs-Sera D, Cokus S, Pellegrini M, Kim J, Miller JF, Hatfull GF, Modlin RL (2012) Propionibacterium acnes Bacteriophages Display Limited Genetic Diversity and Broad Killing Activity against Bacterial Skin Isolates. mBio 3: 5-12.

50. Sheng H, Knecht HJ, Kudva IT, Hovde CJ (2006) Application of bacteriophages to control intestinal Escherichia coliO157:H7 levels in ruminants. Appl Environ Microbiol 72: 5359-5366.

51. Sheng H, Knecht HJ (2006) Application of bacteriophages to control intestinal Escherichia coli O157:H7 levels in ruminants. Appl Environ Microbiol. 72: 5359-5366.

52. Kim KP, Klumpp J, Loessner MJ (2007) Enterobacter sakazakii bacteriophages can prevent bacterial growth in reconstituted infant formula. Int J Food Microbiol 115: 195203.

53. Available at. http://aac.asm.org/content/45/3/649.full

54. Westwater C, Kasman LM, Schofield DA, Werner PA, Dolan, JW, Schmid MG, Norris JS (2003) Use of genetically engineered phage to deliver antimicrobial agents to bacteria: an alternative therapy for treatment of bacterial infections. Antimicrob Agents Chemother 47: 1301-1307

55. Curtin J, Donlan R (2006) Using bacteriophages to reduce formation of catheter-associated biofilms by Staphylococcus epidermidis. Antimicrob Agents Chemother 50: 1268-1275.

56. Lu T, Collins J (2007) Dispersing biofilms with engineered enzymatic bacteriophage. Proc Natl Acad Sci U S A 104: 1197-1202.

57. Wilkinson A, Holme S, Pitts K (2007) SASP: a novel antibacterial DNA binding protein and its targeted delivery for Staphylococcus aureus [abstract F1-2132]. In: Program and abstracts of the 47th Interscience Conference on Antimicrobial Agents and Chemotherapy (Chicago). Washington, DC: American Society of Microbiology.

58. Setlow J, Randesi M, Adams J, Setlow B, Setlow P (1992) Mutation and killing of Escherichia coli expressing a cloned Bacillus subtilis gene whose product alters DNA conformation. J Bacteriol 174: 2943-2950.

59. Fairhead HM (2001) inventor; Phico Therapeutics, assignee. Small acid-soluble proteins and uses thereof. UK patent EP1343896.

60. Fiorentin L, Vieira ND, Barioni W Jr (2005) Oral treatment with bacteriophages reduces the concentration of Salmonella enteritidis PT4 in caecal contents of broilers. Avian Pathol 34: 258-263.

61. Parviz MS, Mansel W (2010) In Sabour PM and Griffiths M, editors. Bacteriophages in the Control of Food- and Waterborne Pathogens. Editor. Amerdican Society for Microbiology -Medical Press p. 333

62. Kutateladze M, Adamia R (2010) Bacteriophages as potential new therapeutics to replace or supplement antibiotics. Trends in Biotechnology. 28: 591-595.

63. Svoboda E (2009) The Next Phage. Popular Science. Available at: http://www.popsci.com/scitech/article/200903/next-phage. Accessed on 31 March, 2009

\section{Corresponding author}

Zhabiz Golkar, $\mathrm{PhD}$

South Carolina Center for Biotechnology

Claflin University

400 Magnolia Street

Orangeburg, SC 29115, USA

Phone: (803) 535-5502

Fax: (803) 535-5776

Email: zgolkar@claflin.edu,

Email: zhabizg@yahoo.com

Conflict of interests: No conflict of interests is declared. 